\title{
Intracorporeal versus extracorporeal anastomosis in right hemicolectomy: a systematic review and meta-analysis
}

\author{
Stefan van Oostendorp ${ }^{1} \cdot$ Arthur Elfrink $^{1} \cdot$ Wernard Borstlap $^{2} \cdot$ Linda Schoonmade $^{3}$. \\ Colin Sietses $^{4} \cdot$ Jeroen Meijerink $^{1} \cdot$ Jurriaan Tuynman $^{1}$
}

Received: 12 January 2016/Accepted: 9 May 2016/Published online: 10 June 2016

(c) The Author(s) 2016. This article is published with open access at Springerlink.com

\begin{abstract}
Background Laparoscopic right hemicolectomy for colon cancer is associated with substantial morbidity despite the introduction of enhanced recovery protocols and laparoscopic surgery. Laparoscopic right hemicolectomy with an intracorporeal anastomosis (IA) is less invasive than laparoscopic assisted hemicolectomy, possibly leading to further decrease in post-operative morbidity and faster recovery. The current standard technique includes an extracorporeal anastomosis with mobilization of the colon, mesenteric traction and a extraction wound located in the mid/upper abdomen with relative more post-operative morbidity compared to extraction wounds located in the lower abdomen.

Methods A systematic review of PubMed and Embase databases was performed on studies comparing the intracorporeal versus the extracorporeal performed anastomosis in laparoscopic right hemicolectomy. Primary outcomes were mortality, short-term morbidity and length of stay. For quality assessment, the MINORS checklist was used. Meta-analysis was performed using a random-effects model, and a subgroup
\end{abstract}

Stefan van Oostendorp

s.vanoostendorp@vumc.nl

1 Department of Surgery, VU University Medical Centre, De Boelelaan 1117, Postbus 7057, 1007 MB Amsterdam, The Netherlands

2 Department of Surgery, Academic Medical Center, Amsterdam, The Netherlands

3 Medical Library, VU University Medical Centre, Amsterdam, The Netherlands

4 Department of Surgery, Gelderse Vallei Hospital Ede, Ede, The Netherlands analysis was performed for data regarding short-term morbidity and length of stay in studies published in 2012 $\geq$.

Results A total of 2692 papers were identified, 12 nonrandomized comparative studies were included in the analysis with a total number of 1492 patients. No significant change in mortality was found (OR $0.36,95 \% \mathrm{CI}$ $\left.0.09-1.46 ; \quad I^{2}=0 \%\right)$. Short-term morbidity decreased significantly in favour of IA (OR $0.68,95 \%$ CI $0.49-0.93$; $\left.I^{2}=20 \%\right)$. Length of stay was decreased, but with serious risk of heterogeneity (MD -0.77 days, $95 \% \mathrm{CI}-1.46$ to $\left.-0.07 ; I^{2}=81 \%\right)$. Subgroup analysis for papers published in $2012 \geq$ resulted in an even larger decrease in short-term morbidity (OR $0.65,95 \%$ CI $0.50-0.85$; $\left.I^{2}=0 \%\right)$ and a significant decrease in length of stay with low risk of heterogeneity (MD -0.77 days, $95 \% \mathrm{CI}-1.17$ to $-0.37 ; I^{2}=4 \%$ ).

Conclusion Intracorporeal anastomosis in laparoscopic right hemicolectomy is associated with reduced short-term morbidity and decreased length of hospital stay suggesting faster recovery as shown in this meta-analysis.

Keywords Laparoscopy · Right hemicolectomy · Totally laparoscopic · Laparoscopic assisted · Intracorporeal ·

Extracorporeal $\cdot$ Anastomosis

\section{Background}

Colorectal carcinoma is the second most common form of cancer in the western world, with an estimated incidence of 1.36 million cases in 2012 worldwide [1, 2]. Right sided hemicolectomy for right sided colonic cancer is a common performed procedure [3]. Currently, in most countries, the laparoscopic assisted right hemicolectomy with an extracorporeal anastomotic (EA) technique is the standard 
technique. However, despite introduction of laparoscopic surgery [4] and enhanced recovery protocols [5] in colorectal surgery, morbidity remains substantial. Large randomized trials and national registry data show that the overall in hospital morbidity is still approximately $30 \%[3,5,6]$.

Morbidity associated with laparoscopic right hemicolectomy includes prolonged ileus, pain-associated decreased pulmonary function and wound infection leading to subsequent increased length of stay $[3,5,6]$. The current standard procedure for laparoscopic right hemicolectomy includes formation of an extracorporeal anastomosis requiring mobilization of the colon and mesenteric traction in order to extract the ileum and ascending colon theoretically leading to more surgical trauma [7]. Furthermore, the EA technique requires the extraction wound to be located in the mid/upper abdomen with relative more post-operative morbidity compared to a wound in the lower abdomen, since it is known that an incision in the mid/upper abdomen tend to result in increased post-operative pain and compromise pulmonary function compared to lower extraction wounds such as the Pfannenstiel [5, 8].

Recent developments in minimal invasive techniques have facilitated intracorporeal stapled anastomosis (IA). This technique enables a smaller extraction wound in the lower abdominal wall and enables a resection of the right colon with less mobilization and mesenteric traction. Potentially, the risk of mesenteric twisting is less compared to the EA technique [9]. Disadvantages of the intracorporeal anastomosis technique include a longer learning curve and laparoscopic skills including suturing and a risk of intraabdominal faecal spillage [10]. Despite potential benefits of the intracorporeal technique, previous reviews published in 2013 failed to show clear advantages of the newer technique $[11,12]$. Since the more recently published studies [13-19] show benefits in short-term morbidity and shorter length of stay for the IA technique, we have conducted an up-to-date systematic review with the most recent studies to investigate the value of the intracorporeal anastomotic technique for laparoscopic right hemicolectomy. We hypothesized that an intracorporeal performed anastomosis leads to a decrease in short morbidity resulting in a shorter length of stay. Secondary endpoints include anastomotic leakage, ileus, incisional surgical site infection and incisional hernia. This systematic review aims to provide a complete overview of studies comparing both techniques.

\section{Methods}

A systematic literature review was performed according to guidelines from the Preferred Reporting Items for Systematic Reviews and Meta-Analyses checklist (PRISMA) [20].

\section{Search strategy}

A comprehensive search was performed in the bibliographic databases PubMed and Embase from inception to 21 December 2015, in collaboration with a medical librarian. Search terms included controlled terms (Mesh in PubMed, Emtree in Embase), as well as free-text terms. The following terms were used (including synonyms and closely related words) as index terms or free-text words: 'colectomy', 'anastomosis', 'intracorporeal', 'extracorporeal' and 'laparoscopy'. The search was performed without date, language or publication status restriction. All titles were screened, and appropriate abstracts were reviewed. See 'Appendix' for the search strategy.

\section{In- and exclusion criteria}

Studies eligible for inclusion were: RCT's, comparative studies on intra- versus extracorporeal anastomosis in laparoscopic right hemicolectomy, and human studies. Exclusion criteria were: non-right hemicolectomy (i.e. transverse or left hemicolectomy, sigmoidectomy, subtotal colectomy), non-comparative (case series, description of technique), single-incision surgery, purely robotic surgery and open hemicolectomy.

\section{Selection process}

After removal of duplicates, two independent reviewers ( $\mathrm{SvO}$ and $\mathrm{AE}$ ) selected the studies by screening on title and abstract. If necessary, a third author was consulted in case of disagreement. Two reviewers ( $\mathrm{SvO}$ and $\mathrm{AE})$ analysed the resulting papers in full text using the online Covidence review manager (Covidence online review manager 2015, www.covidence.org). Further studies were identified by reference checking of the included studies.

\section{Quality assessment and scoring}

To asses methodological quality of the included studies, the 'Methodological index for non-randomized studies' (MINORS) instrument was used [21]. We considered follow-up for short-term outcomes as a period 30 days. 'Follow-up period appropriate to the aim of the study' was considered reported inadequate if outcomes were not defined as 30-day complications or 30-day readmission rate. The interval of long- or medium-term follow-up (FU) had to be reported explicitly. 'Loss to follow-up' was scored with 2 points if mentioned explicitly or if it could be derived from the outcomes (i.e. percentage 30-day readmission). If end of the FU-period was not yet achieved in all patients, 'Loss to follow-up' was rewarded 1 point. Prospective collection of data was adequately reported if 
the authors explicitly mentioned the use of a prospectively maintained database.

\section{Outcomes of interest}

Our primary outcomes of interest were short-term morbidity, mortality and length of stay. Secondarily, we looked at the intraoperative outcomes and the rates of anastomotic leak rate, ileus, incisional surgical site infection (SSI) and incisional hernia. Because the definitions of short-term morbidity varied among the included studies, we derived short-term morbidity of each study separately. If the Clavien-Dindo classification for post-operative complications was used, class V (death) was separated from the total of complications to assess mortality. SSI was considered to be a superficial or deep incisional wound infection, but not as an intraabdominal abscess or organ space infection. Incisional hernia was specified to the extraction site and did not include trocar site herniation. It was postulated that the learning curve of the surgeons could have an impact on the outcomes of the IA. Therefore, a subgroup analysis was performed for studies published in 2012 and later on shortterm morbidity and length of stay to see whether the more recent studies showed a larger effect.

\section{Quantitative analysis}

Data analysis was performed with the use of Revman 5.0 (Review Manager 5.0, Copenhagen, Denmark: The Nordic Cochrane Centre, The Cochrane Collaboration, 2008). Dichotomous outcomes were statistically analysed and summarized by using the odds ratio (OR) with a confidence interval (CI) of $95 \%$. Mantel-Haenszel method was used to combine the OR of the outcomes using a random-effects model. Continuous outcomes were analysed by computing a mean difference (MD). OR $<1$ favours the IA group and was considered statistically significant if $p<0.05$ if the $95 \%$ CI did not include 1 . Heterogeneity was assessed by performing an $I^{2}$ statistic and a Chi-squared test, considering $I^{2}>50 \%$ and Chi-squared $p$ value $<0.1$ as statistically significant heterogeneity [22]. A subgroup analysis was done for data regarding short-term morbidity and length of stay in studies published in 2012 $\geq$.

\section{Results}

\section{Literature search}

The search resulted in a total of 2692 papers after removal of duplicates. After screening on title and abstract, 24 papers were assessed by full text. A total of 12 papers were excluded for various reasons $[9,11,12,23-31]$, see Fig. 1.
Finally, 12 studies were incorporated in the qualitative analysis [13-19, 32-36]. For studies with overlap, we included the most recent publications which consisted of more patients $[13,36]$ and excluded the earlier studies $[9,23]$. No additional studies were identified by crosschecking the references of the included papers.

Magistro et al. reported the only prospective study that alternatively assigned patients to the two procedures [14]. Eleven studies were of retrospective design [13, 15-19, 32-36]. Milone et al. [16] matched the control group using a propensity score. Trastulli et al. [18] reported a retrospective multicenter case series on right colectomy comparing robotic intracorporeal anastomosis to laparoscopic intracorporeal anastomosis and laparoscopic extracorporeal anastomosis. The included studies resulted in a total number of 1492 participants who underwent a laparoscopic right hemicolectomy further specified to 763 and 729 patients for intra- or extracorporeal anastomosis, respectively. Study design and patient characteristics are described in Table 1. In nine studies, the intracorporeal performed anastomosis was created using a mechanical stapler with [13-15, 17-19, 33, 35, 36] or without [16] additional sutures in the IA technique. A mechanical stapler was most commonly used for the extracorporeal anastomosis as well (with $[13,14,18,36]$ or without $[16,19]$ additional sutures). One study made a hand-sewn anastomosis [15] or according to the preference of the individual surgeon (mechanical or hand-sewn) [17, 33]. Two studies did not specify the creation of the anastomosis [32, 34].

\section{Quality assessment: MINORS instrument}

The quality assessment is shown in Table 2 and Fig. 2. The mean score was 18.8 (range 16-21) out of a total of 24 points. In some studies reporting on mid- or long-term outcomes, the foreseen follow-up period was not achieved in all patients and was regarded as reported but defined as 'not adequately' [13, 17]. Several studies, aiming to compare short-term outcomes, failed to (adequately) report 30-day outcomes including readmission and/or reported no visits to the outpatient clinic after discharge [14, 16, 32]. Interestingly, Scatizzi et al. [36] defined short-term outcomes as 90 days and reported an outpatient clinic visit 8 days after discharge, but subsequently failed to report on the 3 month FU besides readmission. Half of the studies changed their way of operation halfway during the score inclusion period from EA to IA, using their last EA as 'historic' control group [15, 18, 19, 32, 33, 35]. All studies scored low on unbiased assessment of outcomes due to lack of blinding and randomization. None calculated a sample size since 11 studies were retrospective and 1 study was only pseudo-randomized [14]. 
Fig. 1 Flowchart

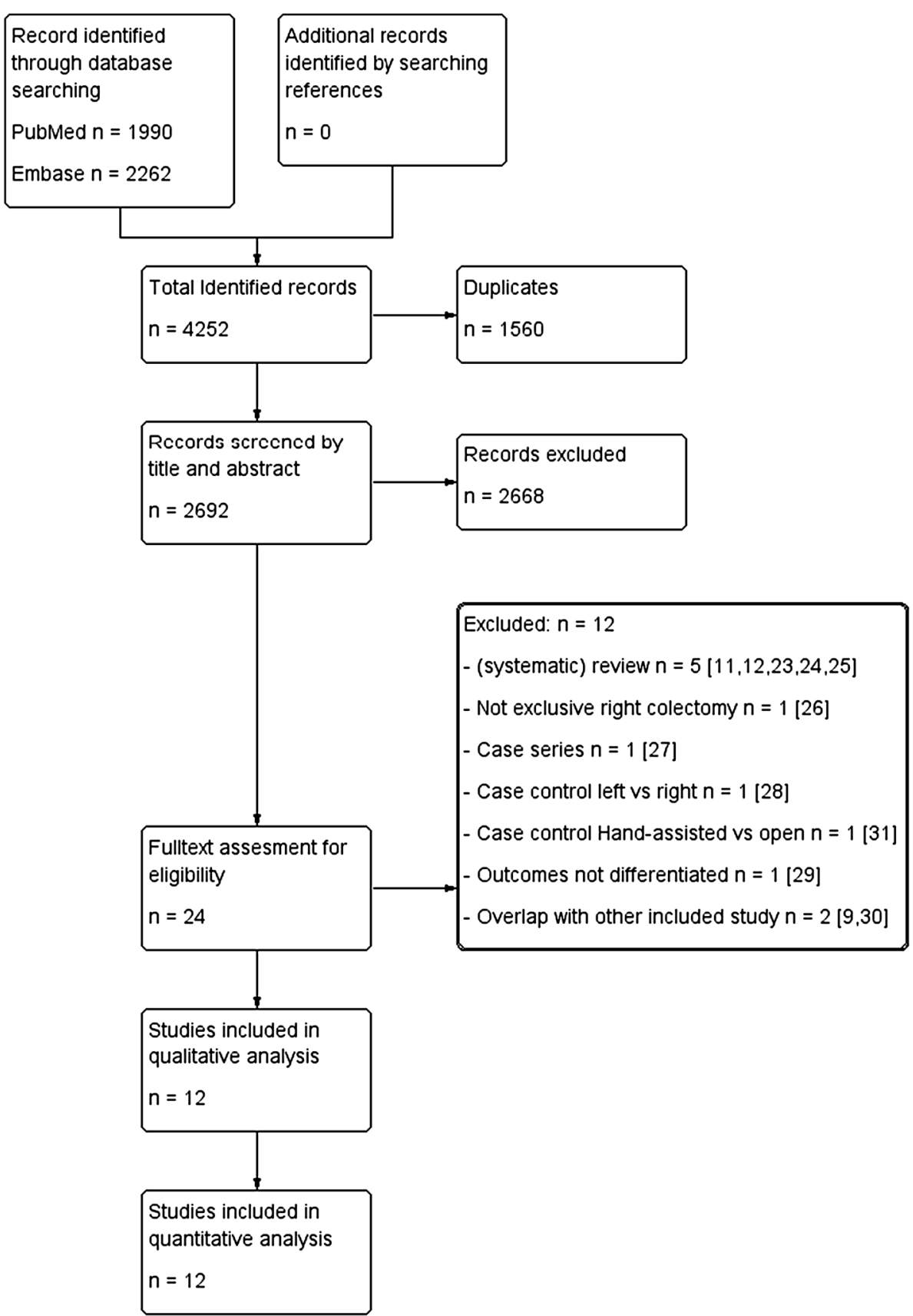

Percentage adequately reported (italics). Percentage reported but inadequate: 1 point (bold). Percentage not reported: 0 points (bold italics).

\section{Primary outcomes}

\section{Mortality}

No significant difference in mortality was observed for both procedures: OR $0.36,95 \%$ CI $0.09-1.46 ; I^{2}=0 \%$ (Fig. 3).

\section{Short-term morbidity}

A significant decrease in short-term morbidity was observed when performing an IA: OR 0.68 , $95 \%$ CI $0.49-0.93$; $I^{2}=20 \%$. Subgroup analysis on studies published $\geq 2012$ showed a larger decrease and less risk at heterogeneity: OR $0.65,95 \%$ CI $0.50-0.85 ; I^{2}=0 \%$. Four studies reported morbidity according to Clavien-Dindo [15-17, 35]. Two other studies reported 30-day complication rate [18, 33]. One study described the amount of complications in text [32]. The remaining studies provided a table of complications 


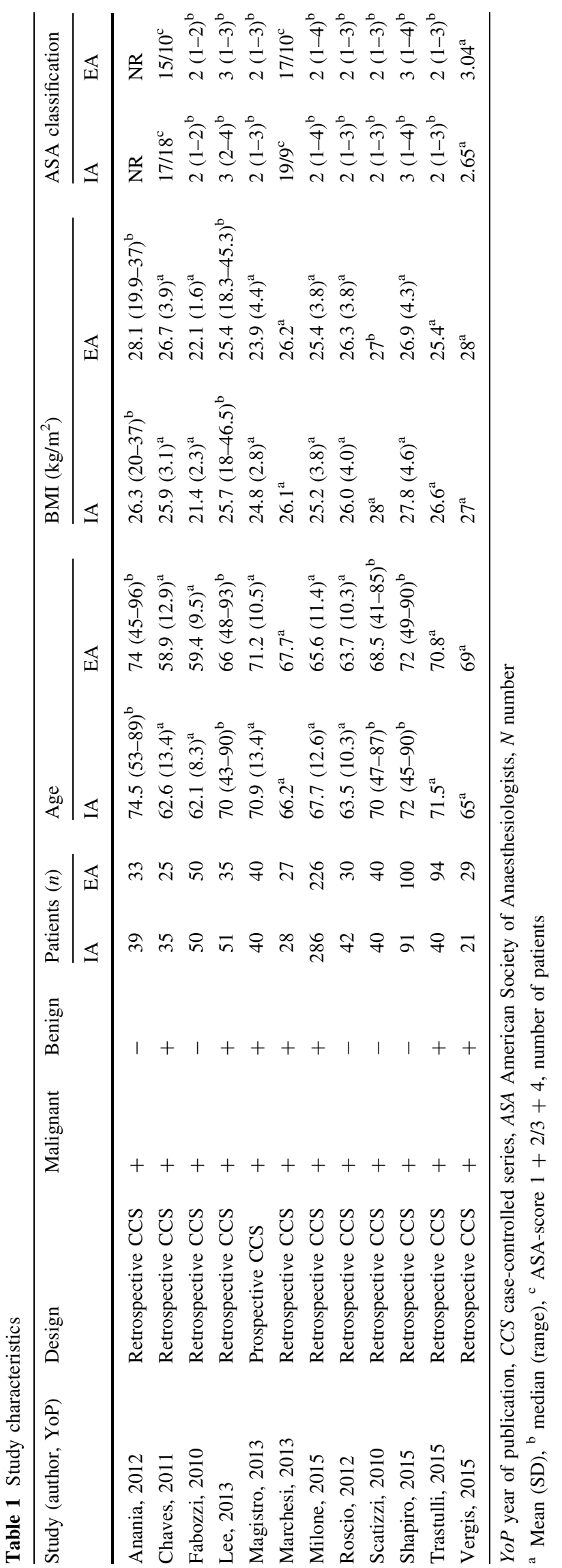




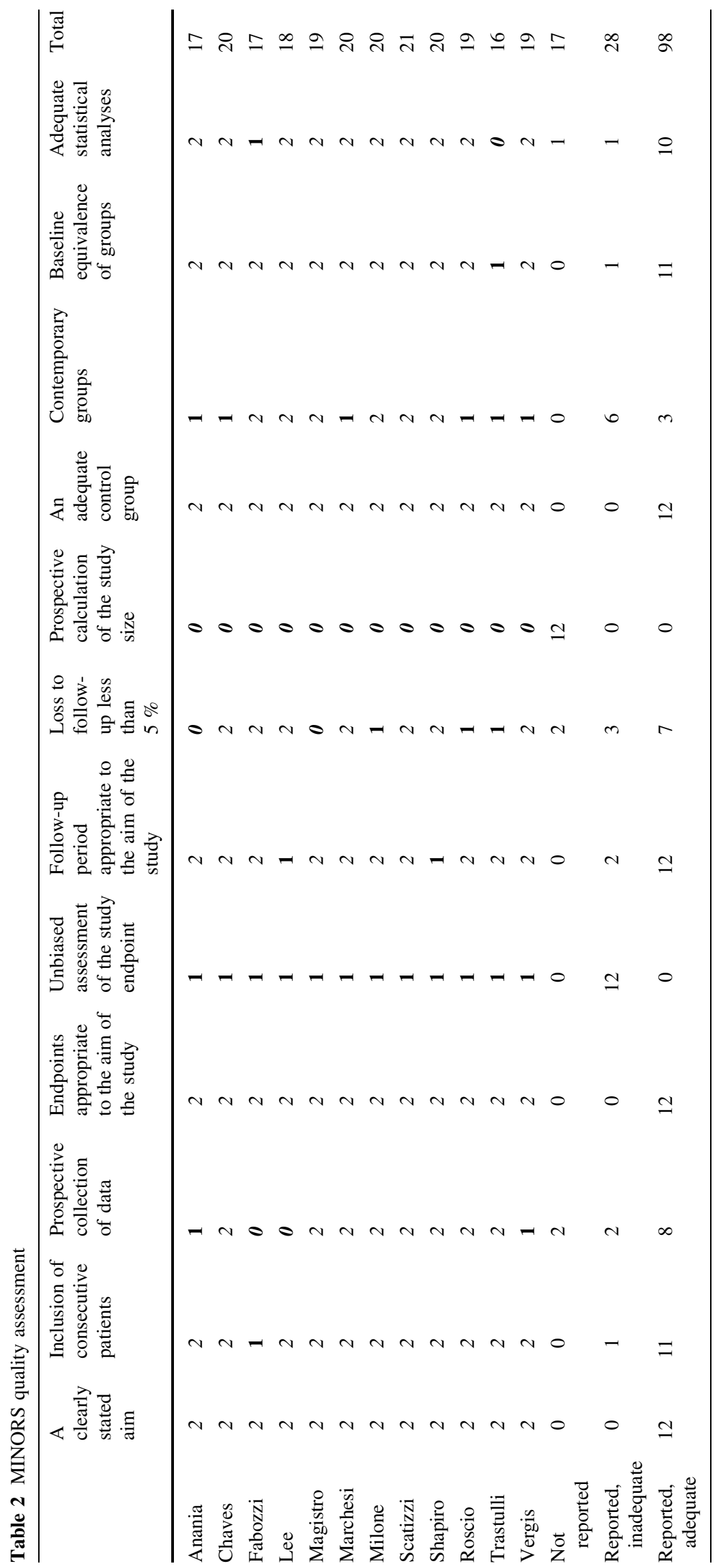




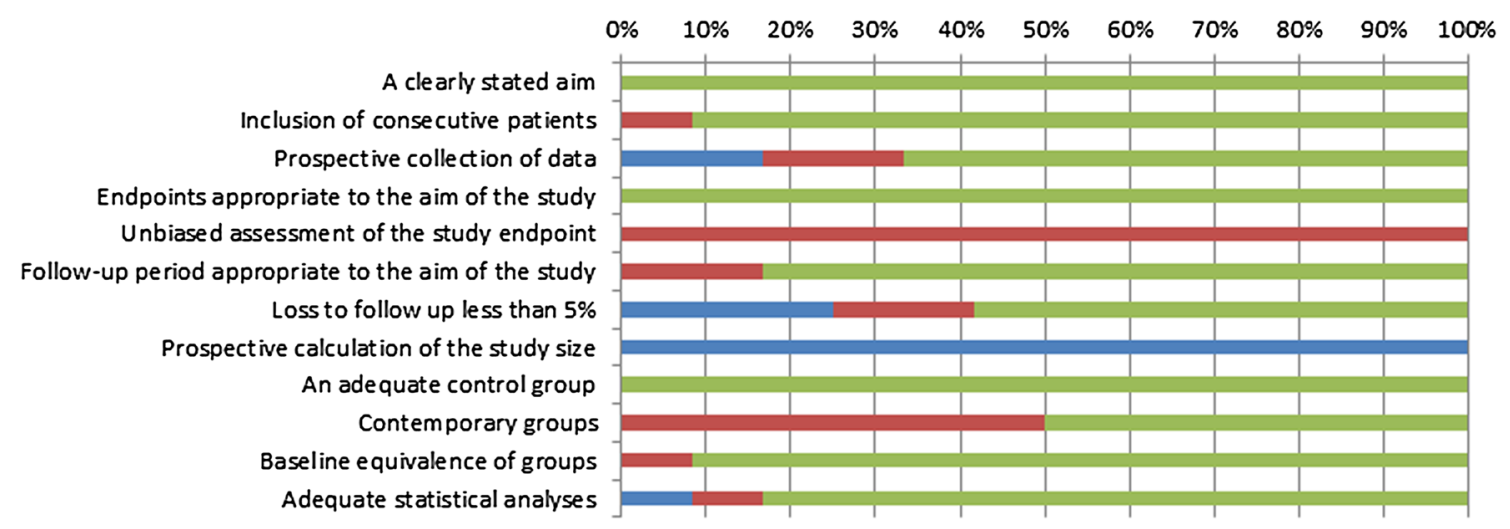

Fig. 2 MINORS quality assessment

\begin{tabular}{|c|c|c|c|c|c|c|c|c|c|c|}
\hline \multirow[b]{2}{*}{ Study or Subgroup } & \multicolumn{2}{|c|}{ Intracorporeal } & \multicolumn{2}{|c|}{ Extracorporeal } & \multirow[b]{2}{*}{ Weight } & \multirow{2}{*}{$\begin{array}{c}\text { Odds Ratio } \\
\text { M-H, Random, } 95 \% \mathrm{Cl}\end{array}$} & & \multirow{2}{*}{\multicolumn{2}{|c|}{$\begin{array}{c}\text { Odds Ratio } \\
\text { M-H, Random, } 95 \% \mathrm{Cl}\end{array}$}} & \\
\hline & Events & Total & Events & Total & & & & & & \\
\hline Anania 2012 & 0 & 39 & 0 & 33 & & Not estimable & & & & \\
\hline Chaves 2011 & 1 & 35 & 1 & 25 & $24.6 \%$ & $0.71[0.04,11.85]$ & & & & \\
\hline Fabozzi 2010 & 0 & 50 & 0 & 50 & & Not estimable & & & & \\
\hline Lee 2013 & 0 & 51 & 0 & 35 & & Not estimable & & & & \\
\hline Magistro 2013 & 0 & 40 & 1 & 40 & $18.7 \%$ & $0.33[0.01,8.22]$ & & & & \\
\hline Marchesi 2013 & 0 & 28 & 0 & 27 & & Not estimable & & & & \\
\hline Milone 2015 & 0 & 286 & 1 & 226 & $19.0 \%$ & $0.26[0.01,6.47]$ & & & & \\
\hline Roscio 2012 & 0 & 42 & 1 & 30 & $18.7 \%$ & $0.23[0.01,5.88]$ & & & & \\
\hline Scatizzi 2010 & 0 & 40 & 0 & 40 & & Not estimable & & & & \\
\hline Shapiro 2015 & 0 & 91 & 1 & 100 & $18.9 \%$ & $0.36[0.01,9.01]$ & & & & \\
\hline Trastulli 2015 & 0 & 40 & 0 & 94 & & Not estimable & & & & \\
\hline Vergis 2015 & 0 & 21 & 0 & 29 & & Not estimable & & & & \\
\hline Total $(95 \% \mathrm{Cl})$ & & 763 & & 729 & $100.0 \%$ & $0.36[0.09,1.46]$ & & & & \\
\hline Total events & 1 & & 5 & & & & & & & \\
\hline $\begin{array}{l}\text { Heterogeneity: } \mathrm{Tau}^{2}= \\
\text { Test for overall effect: }\end{array}$ & $\begin{array}{l}0.00 ; \mathrm{Chi}^{2} \\
\mathrm{Z}=1.42(\mathrm{P}\end{array}$ & $\begin{array}{l}0.33, \mathrm{df} \\
=0.15)\end{array}$ & $f=4(P=c$ & $9) ; 1^{2}=$ & & & $\frac{1}{0.01}$ & $\begin{array}{l}0.1 \\
\text { Favours }[\mathrm{IA}]\end{array}$ & $\begin{array}{cc}1 & 10 \\
1 & 10 \\
\text { ] Favours [EA] }\end{array}$ & 100 \\
\hline
\end{tabular}

Fig. 3 Mortality

differentiated to mortality, minor and major morbidity [13, 14, 34, 36] (Fig. 4).

\section{Length of stay}

In the meta-analysis, Length of stay (LoS) was significantly decreased if favour of IA: MD -0.77 days, $95 \% \mathrm{CI}-1.46$ to -0.07 . However, heterogeneity among studies was substantial. Subgroup analysis on studies published $\geq 2012$ was more homogenous and showed a statistically significant decrease in $\operatorname{LoS}(0.77$ days, $95 \%$ CI -1.17 to -0.37$)$ (Fig. 5). Two studies were not included in the meta-analysis. Trastulli et al. [18] provided a median (range) of 5.5 days (3-14) for IA versus 7 (4-21) in the EA group. The mean LoS in the study by Vergis et al. [19] was 5.33 and 5.86 for IA and EA, respectively. Unfortunately, no SD was provided.

\section{Secondary outcomes}

\section{Intraoperative outcomes}

Duration of surgery Operating time varied widely, with conflicting significant outcomes in either IA or EA. Magistro et al. and Shapiro et al. reported a significant longer duration of surgery (DoS) for IA [14, 17]. In contrast, Fabozzi et al. [34] and Roscio et al. [35] stated the IA technique was faster. However, most studies showed no significant difference. Interestingly, Marchesi et al. reported the time to perform the anastomosis separately and showed an impressive reduction at the end of his IA series indicating a learning curve. The mean DoS of his last 10 IA was 161 min versus his mean EA time of 186.8 min [15]. See 'Appendix'. 


\begin{tabular}{|c|c|c|c|c|c|c|c|c|c|c|}
\hline \multirow[b]{2}{*}{ Study or Subgroup } & \multicolumn{2}{|c|}{ Intracorporeal } & \multicolumn{2}{|c|}{ Extracorporeal } & \multirow[b]{2}{*}{ Weight } & \multirow{2}{*}{$\begin{array}{l}\text { Odds Ratio } \\
\text { M-H, Random, } 95 \% \mathrm{Cl}\end{array}$} & \multirow{2}{*}{\multicolumn{4}{|c|}{$\begin{array}{l}\text { Odds Ratio } \\
\mathrm{M}-\mathrm{H}, \text { Random, } 95 \% \mathrm{Cl}\end{array}$}} \\
\hline & Events & Total & Events & Total & & & & & & \\
\hline \multicolumn{11}{|c|}{ 1.3.1 Published before 2012} \\
\hline Chaves 2011 & 5 & 35 & 4 & 25 & $4.5 \%$ & $0.88[0.21,3.65]$ & & & & \\
\hline Fabozzi 2010 & 0 & 50 & 14 & 50 & $1.2 \%$ & $0.02[0.00,0.43]$ & & & & \\
\hline Roscio 2012 & 8 & 42 & 8 & 30 & $7.0 \%$ & $0.65[0.21,1.98]$ & & & & \\
\hline $\begin{array}{l}\text { Scatizzi } 2010 \\
\text { Subtotal }(95 \% \mathrm{Cl})\end{array}$ & 5 & $\begin{array}{r}40 \\
167\end{array}$ & 3 & $\begin{array}{r}40 \\
145\end{array}$ & $\begin{array}{r}4.1 \% \\
16.9 \%\end{array}$ & $\begin{array}{l}1.76[0.39,7.93] \\
0.59[0.16,2.14]\end{array}$ & & & & \\
\hline Total events & 18 & & 29 & & & & & & & \\
\hline \multicolumn{11}{|c|}{$\begin{array}{l}\text { Heterogeneity: } \mathrm{Tau}^{2}=1.05 ; \mathrm{Chi}^{2}=8.10, \mathrm{df}=3(P=0.04) ; \mathrm{I}^{2}=63 \% \\
\text { Test for overall effect: } Z=0.81(P=0.42)\end{array}$} \\
\hline \multicolumn{11}{|l|}{ 1.3.2 Published 2012+ } \\
\hline Lee 2013 & 28 & 51 & 16 & 35 & $10.7 \%$ & $1.45[0.61,3.43]$ & & & & \\
\hline Magistro 2013 & 7 & 40 & 8 & 40 & $6.9 \%$ & $0.85[0.28,2.61]$ & & & & \\
\hline Marchesi 2013 & 3 & 28 & 5 & 27 & $3.9 \%$ & $0.53[0.11,2.47]$ & & & & \\
\hline Milone 2015 & 93 & 286 & 97 & 226 & $30.3 \%$ & $0.64[0.45,0.92]$ & & - & & \\
\hline Shapiro 2015 & 18 & 91 & 37 & 100 & $16.0 \%$ & $0.42[0.22,0.81]$ & & - & & \\
\hline Trastulli 2015 & 8 & 40 & 27 & 94 & $10.1 \%$ & $0.62[0.25,1.52]$ & & $\Rightarrow$ & & \\
\hline $\begin{array}{l}\text { Vergis } 2015 \\
\text { Subtotal }(95 \% \mathrm{Cl})\end{array}$ & 10 & $\begin{array}{r}15 \\
551\end{array}$ & 21 & $\begin{array}{r}29 \\
551\end{array}$ & $\begin{array}{r}5.0 \% \\
83.1 \%\end{array}$ & $\begin{array}{c}0.76[0.20,2.93] \\
0.65[0.50,0.85]\end{array}$ & & $\vec{v}$ & & \\
\hline Total events & 167 & & 211 & & & & & & & \\
\hline \multicolumn{11}{|c|}{$\begin{array}{l}\text { Heterogeneity: } \mathrm{Tau}^{2}=0.00 ; \mathrm{Chi}^{2}=5.34, \mathrm{df}=6(P=0.50) ; \mathrm{I}^{2}=0 \% \\
\text { Test for overall effect: } Z=3.14(P=0.002)\end{array}$} \\
\hline Total $(95 \% \mathrm{Cl})$ & & 718 & & 696 & $100.0 \%$ & $0.68[0.49,0.93]$ & & $V$ & & \\
\hline Total events & 185 & & 240 & & & & & & & \\
\hline $\begin{array}{l}\text { Heterogeneity: } \mathrm{Tau}^{2} \\
\text { Test for overall effect } \\
\text { Test for subgroup diff }\end{array}$ & $\begin{array}{l}0.05 ; \mathrm{Chi}^{2} \\
\mathrm{Z}=2.40(\mathrm{~F} \\
\text { rences: } \mathrm{Cr}\end{array}$ & $\begin{array}{r}12.44 \\
=0.02) \\
=0.03\end{array}$ & $\begin{array}{l}d f=10(P \\
d f=1(P\end{array}$ & $0.26) ;$ । & $2=20 \%$ & & 0.001 & $\begin{array}{c}0.1 \\
\text { Favours }[\mathrm{IA}]\end{array}$ & $\begin{array}{l}10 \\
\text { Favours [EA] }\end{array}$ & 1000 \\
\hline
\end{tabular}

Fig. 4 Short-term morbidity

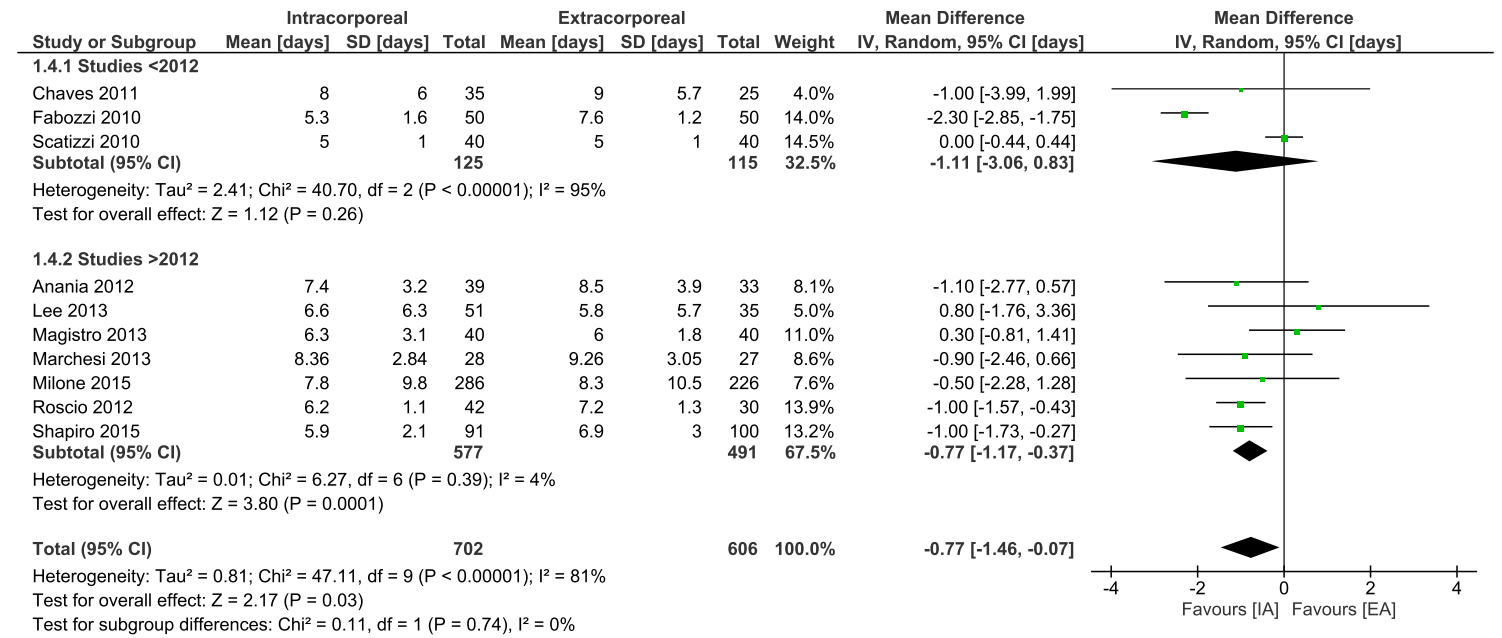

Fig. 5 Length of stay

\section{Post-operative outcomes}

Anastomotic leak rate No statistically significant difference between the IA or EA technique was found for anastomotic leakage: OR $0.77,95 \%$ CI $0.39-1.49$; $I^{2}=0 \%$ (Fig. 6).

Ileus The incidence of an ileus was reported in 6 studies [13-18, 33], no significant change was found: OR 0.94, $95 \%$ CI $0.57-1.57 ; I^{2}=0 \%$ (Fig. 7).
Surgical site infection All but one study [32] mentioned the occurrence of a surgical site infection (please note: superficial and deep incisional surgical site infection, not abscess or organ spaced SSI). A significant decrease in SSI was found (OR $0.56,95 \%$ CI $0.35-0.88 ; I^{2}=0 \%$.) in favour of IA (Fig. 8).

Incisional hernia Five studies reported incisional hernia, see 'Appendix'. No meta-analysis was performed since follow-up and extraction technique varied. For instance, all 


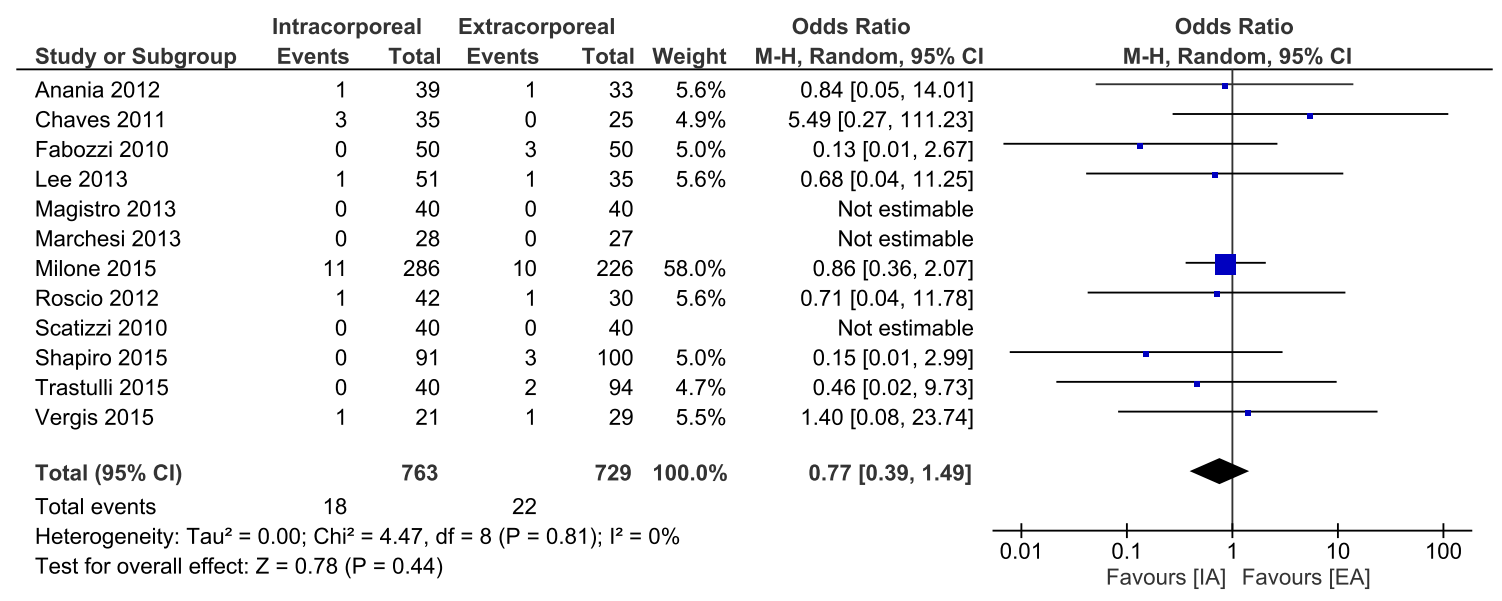

Fig. 6 Anastomotic leak

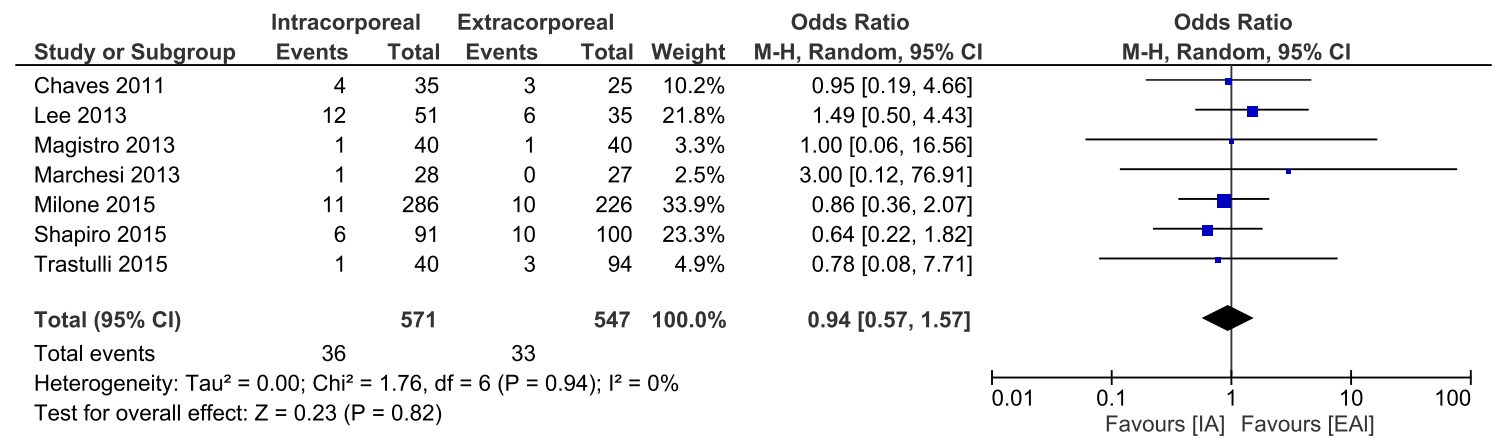

Fig. 7 Ileus

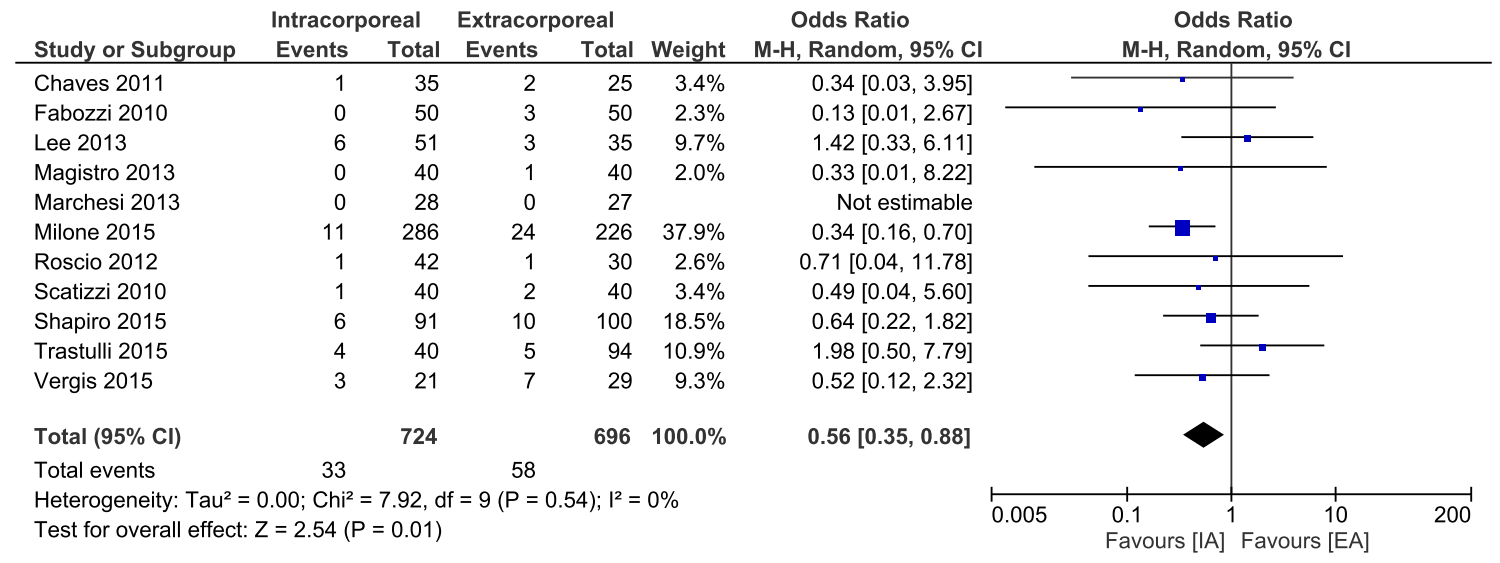

Fig. 8 Surgical site infection

the hernia's in the IA group by Shapiro $(n=2)$ and Chaves ( $n=2$ ) was observed in patients having had an extraction other than the routinely performed Pfannenstiel incision.

Return of bowel function There was a variety in reporting on return of bowel function among included studies. Four studies [32, 33, 35, 36] showed significant earlier bowel movement in the IA group, and two different papers [14, 16] reported significant earlier first flatus pointing towards an sooner return of bowel function for IA. See 'Appendix'.

\section{Discussion}

This systematic review comparing intracorporeal versus extracorporeal anastomosis in laparoscopic right hemicolectomy shows that the intracorporeal technique is 
associated with significant decreased short-term morbidity and length of stay. No differences were observed for mortality, Ileus and anastomotic leakage. In a subgroup analysis of the more recent studies $(2012 \geq)$, the observed differences were larger with less heterogeneity in favour of IA.

The observed decreased morbidity of the intracorporeal anastomosis technique seems largely related to the extraction site. By performing an IA, the incision for specimen extraction can be smaller and the incision can be performed in the lower part of the abdomen, which has shown to be associated with less pain, less pulmonary morbidity, a lower infection rate and on the long-term lower herniation rate $[37,38]$. The suprapubic (Pfannenstiel) site for specimen extraction is the preferred extraction site since it has been reported to be associated with low site infections and with a low hernia rate of only $0-2 \%$ [39]. Shapiro et al. [17] found such hernia rates in their series (IA $2.2 \%$, EA $17 \%$ ). The 2 hernia's in the IA were not Pfannenstiel incisions but periumbilical and midline. Chaves et al. [33] report 2 versus 1 hernia in IA and EA, respectively. However, again these two cases in the IA-arm were not extracted by a Pfannenstiel incision, but a midline incision was chosen since both patients had a previous laparotomy. Furthermore, IA requires a smaller incision potentially leading to less post-operative pain [40] with a possible reduction in hospital costs [41], shorter hospital stay [4] and pulmonary dysfunction [8]. The observed decreased morbidity in the IA group might also be related to less mobilization of the transverse colon and less traction on the mesentery and pancreatico-duodenal block, theoretically resulting in surgical trauma and earlier restoration of bowel function [19,35]. Especially, in obese patients, the mesentery is subject to substantial traction to externalize the bowel in EA [12, 25, 33, 42, 43].

Total mortality did not statistically differ. Short-term morbidity was significantly decreased in favour of IA. This advantage was even larger for the more recent studies as shown after subgroup analysis. The length of stay seems shorter; however, this was not significant. In addition, serious risk at heterogeneity was observed in the metaanalysis, so no conclusions can be made. However, subgroup analysis of the recent studies did reveal an significant decrease in LoS in favour of IA as is expected since the morbidity is less. See Fig. 5.

Incisional SSI was significantly decreased when an IA was performed. Some authors discussed that externalizing the bowel in EA requires more traction and tension of the wound resulting in more tissue trauma [26]. No significant differences in anastomotic leak and ileus rate were found. In contrast, using IA technique, the necessity for intraperitoneal tomies into the contaminated transversum and ileum could lead to a theoretical increase of intraabdominal infections. Chang et al. [44] described the use of atraumatic intracorporeal bulldogs to minimize faecal spillage when performing an IA. Since the included studies heterogeneously reported on intraabdominal abscesses and/or interventions, we cannot conclude that the IA has a significant influence on deep abdominal abscesses compared to standard EA.

Potential new techniques for extraction include transvaginal colectomy, a form of natural orifice specimen extraction (NOSE). This might even further decrease surgical trauma, although large cohort data and randomized evidence is lacking [45]. Nevertheless, small cohort series show promising results for partial colectomy with minor short-term morbidity and a shorter length of stay [45, 46]. For male, transgastric or transrectal extraction creates potential more surgical trauma, and a small Pfannenstiel is still considered as the best option. Currently, the available data are insufficient to make any statements regarding safety and efficacy of natural orifice transluminal endoscopic surgery (NOTES) for laparoscopic right hemicolectomy.

This systematic review and meta-analysis has several limitations. The included studies are merely observational, and the majority ( $n=11$ out of 12 ) was of retrospective design. Complications according to Clavien-Dindo classification were reported only in $25 \%$ of the included studies. Studies focused merely on short-term outcomes and reported corresponding follow-up. As we foresee, a considerable reduction in the incidence of incisional hernia following IA technique, and longer follow-up (i.e. 2 years) would provide more insight [37].

\section{Conclusion}

This meta-analysis of non-randomized, comparative studies shows that intracorporeal anastomosis in laparoscopic right hemicolectomy is associated with reduced short-term morbidity and decreased length of hospital stay suggesting faster recovery. A randomized controlled trial is warranted to confirm these findings.

\section{Compliance with ethical standards}

Disclosures Stefan van Oostendorp, Arthur Elfrink, Wernard Borstlap, Linda Schoonmade, Colin Sietses, Jeroen Meijerink and Jurriaan Tuynman declare that they have no conflict of interest.

Open Access This article is distributed under the terms of the Creative Commons Attribution 4.0 International License (http://crea tivecommons.org/licenses/by/4.0/), which permits unrestricted use, distribution, and reproduction in any medium, provided you give appropriate credit to the original author(s) and the source, provide a link to the Creative Commons license, and indicate if changes were made. 


\section{Appendix}

See Tables 3, 4, 5, 6, 7 and 8 .

Table 3 PubMed search 21 December 2015

\begin{tabular}{|c|c|c|}
\hline & PubMed search 21 December 2015 & $N$ \\
\hline \#1 & $\begin{array}{l}\text { ‘Colectomy’[Mesh:NoExp] OR colectom*[tiab] OR hemicolectom*[tiab] OR colon resection*[tiab] OR colorectal } \\
\text { resection*[tiab] OR large bowel resection*[tiab] }\end{array}$ & 21,875 \\
\hline \#2 & 'Anastomosis, Surgical'[Mesh:NoExp] OR anastom*[tiab] & 80,578 \\
\hline \#3 & $\begin{array}{l}\text { intracorpo*[tiab] OR intra-corpo*[tiab] OR intra-abdom*[tiab] OR intraabdom*[tiab] OR ICA[tiab] OR extracorpo*[tiab] OR } \\
\text { extra-corpo*[tiab] OR extra-abdom*[tiab] OR extraabdom*[tiab] OR ECA[tiab] }\end{array}$ & 71,900 \\
\hline \#4 & $((' L a p a r o s c o p y ’[$ Mesh:NoExp] OR laparoscop*[tiab]) AND (total*[tiab] OR assisted[tiab])) & 24,110 \\
\hline \#5 & \#2 AND \#3 & 2756 \\
\hline \#6 & $\# 4$ or \#5 & 26,407 \\
\hline \#7 & \#1 AND \#6 & 1990 \\
\hline
\end{tabular}

Table 4 Embase search 21 December 2015

\begin{tabular}{|c|c|c|}
\hline & Embase search 21 December 2015 & $N$ \\
\hline \#1 & $\begin{array}{l}\text { 'colon resection'/de OR 'hemicolectomy'/exp OR colectom*:ab,ti OR hemicolectom*:ab,ti OR (colon NEAR/ } \\
3 \text { resection*):ab,ti OR (colorectal NEAR/3 resection*):ab,ti OR ('large bowel' NEAR/3 resection*):ab,ti }\end{array}$ & 42,437 \\
\hline \#2 & 'anastomosis'/exp OR anastom*:ab,ti & 191,035 \\
\hline \#3 & $\begin{array}{l}\text { intracorpo*:ab,ti OR (intra NEAR/3 corpo*):ab,ti OR (intra NEAR/3 abdom*):ab,ti OR intraabdom*:ab,ti OR ica:ab,ti } \\
\text { OR extracorpo*:ab,ti OR (extra NEAR/3 corpo*):ab,ti OR (extra NEAR/3 abdom*):ab,ti OR extraabdom*:ab,ti } \\
\text { OR eca:ab,ti }\end{array}$ & 93,326 \\
\hline \#4 & laparoscopy'/exp OR laparoscop*:ab,ti AND (total*:ab,ti OR assisted:ab,ti) & 39,455 \\
\hline$\# 5$ & \#2 AND \#3 & 5822 \\
\hline \#6 & \#4 OR \#5 & 44,350 \\
\hline \#7 & \#1 AND \#6 & 3676 \\
\hline \#8 & \#7 AND ('article'/it OR 'article in press'/it OR 'conference paper'/it OR 'review'/it) & 2262 \\
\hline
\end{tabular}

Table 5 Duration of surgery

\begin{tabular}{llll}
\hline Study (author, YoP) & \multicolumn{2}{l}{ Duration of surgery (min) } & \\
\cline { 2 - 4 } & IA & EA & $p$ \\
\hline Anania, 2012 & $186.8(105-280)^{\mathrm{c}}$ & $184.1(115-285)^{\mathrm{c}}$ & 0.6549 \\
Chaves, 2011 & $227(44.5)^{\mathrm{a}}$ & $203(36.4)^{\mathrm{a}}$ & NR \\
Fabozzi, 2010 & $78(25)^{\mathrm{a}}$ & $92(22)^{\mathrm{a}}$ & $<\mathbf{0 . 0 5}$ \\
Lee, 2013 & $205(132)^{\mathrm{a}}$ & $196(56)^{\mathrm{a}}$ & NR \\
Magistro, 2013 & $230(45)^{\mathrm{a}}$ & $203(48)^{\mathrm{a}}$ & $\mathbf{0 . 0 1 1}$ \\
Marchesi, 2013 & $205.79(45.77)^{\mathrm{a}}$ & $196.78(22.95)^{\mathrm{a}}$ & 0.3952 \\
Milone, 2015 & $166.9(10.7)^{\mathrm{a}}$ & $157.5(67.2)^{\mathrm{a}}$ & 0.06 \\
Roscio, 2012 & $176.5(40.0)^{\mathrm{a}}$ & $186.3(40.1)^{\mathrm{a}}$ & 0.039 \\
Scatizzi, 2010 & $150(115-180)^{\mathrm{b}}$ & $150(105-245)^{\mathrm{b}}$ & 0.167 \\
Shapiro, 2015 & $155(37)^{\mathrm{a}}$ & $142(35)^{\mathrm{a}}$ & $\mathbf{0 . 0 0 6}$ \\
Trastulli, 2015 & $204.3(51.9)^{\mathrm{a}}$ & $208(61)^{\mathrm{a}}$ & $\mathrm{NR}$ \\
Vergis, 2015 & $170(121-237)^{\mathrm{b}}$ & $181(98-205)^{\mathrm{b}}$ & 0.78 \\
\hline
\end{tabular}

Bold values are statistically significant $(p<0.05)$

$Y o P$ year of publication, $M i n$ minutes, $N$ number, $N R$ not reported

${ }^{\mathrm{a}}$ Mean (SD), ${ }^{\mathrm{b}}$ median (range), ${ }^{\mathrm{c}}$ mean (range) 
Table 6 Incisional hernia

\begin{tabular}{|c|c|c|c|}
\hline \multirow[t]{2}{*}{ Study (author, YoP) } & \multicolumn{3}{|l|}{$\begin{array}{l}\text { Hernia } \\
n(\%)\end{array}$} \\
\hline & IA & EA & $p$ \\
\hline Anania, 2012 & NR & NR & - \\
\hline Chaves, 2011 & $2(5.7)$ & $1(4)$ & - \\
\hline Fabozzi, 2010 & NR & NR & - \\
\hline Lee, 2013 & $1(1.9)$ & $3(8.6)$ & - \\
\hline Magistro, 2013 & NR & NR & - \\
\hline Marchesi, 2013 & NR & NR & - \\
\hline Milone, 2015 & NR & NR & - \\
\hline Roscio, 2012 & 0 & $1(3.3)$ & - \\
\hline Scatizzi, 2010 & NR & NR & - \\
\hline Shapiro, 2015 & $2(2.2)$ & $17(17.0)$ & 0.001 \\
\hline Trastulli, 2015 & NR & NR & - \\
\hline Vergis, 2015 & 0 & $6(20.7)$ & 0.026 \\
\hline
\end{tabular}

Bold values are statistically significant $(p<0.05)$

$Y o P$ year of publication, $N$ number, $N R$ not reported

Table 7 Return of bowel function

\begin{tabular}{|c|c|c|c|c|c|c|}
\hline \multirow[t]{2}{*}{ Study (author, YoP) } & \multicolumn{3}{|c|}{ Bowel movement (days) } & \multicolumn{3}{|c|}{ First flatus (days) } \\
\hline & IA & EA & $p$ & IA & EA & $p$ \\
\hline Anania, 2012 & $3.8(1.4)^{\mathrm{a}}$ & $4.9(1.5)^{\mathrm{a}}$ & $<0.0001$ & NR & NR & - \\
\hline Chaves, 2011 & $3(2-8)^{\mathrm{b}}$ & $4(2-8)^{\mathrm{b}}$ & 0.004 & NR & NR & - \\
\hline Fabozzi, 2010 & $3.1(1.2)^{\mathrm{a}}$ & $4.4(1.6)^{\mathrm{a}}$ & NS & NR & NR & - \\
\hline Lee, 2013 & NR & NR & - & NR & NR & - \\
\hline Magistro, 2013 & $3.5(1.1)^{\mathrm{a}}$ & $3.8(1.1)^{\mathrm{a}}$ & 0.234 & $2.2(0.6)^{\mathrm{a}}$ & $2.6(0.8)^{\mathrm{a}}$ & 0.043 \\
\hline Marchesi, 2013 & NR & NR & - & NR & NR & - \\
\hline Milone, 2015 & NR & NR & - & $1.7(1)^{\mathrm{a}}$ & $2.3(0.8)^{\mathrm{a}}$ & $<0.001$ \\
\hline Roscio, 2012 & $2.9(0.9)^{\mathrm{a}}$ & $3.4(0.9)^{\mathrm{a}}$ & 0.023 & NR & NR & - \\
\hline Scatizzi, 2010 & $0(0-1)^{\mathrm{b}}$ & $1(0-1)^{\mathrm{b}}$ & 0.043 & NR & NR & - \\
\hline Shapiro, 2015 & NR & NR & - & NR & NR & - \\
\hline Trastulli, 2015 & NR & NR & - & $4(1-7)^{\mathrm{b}}$ & $3(1-6)^{\mathrm{b}}$ & - \\
\hline Vergis, 2015 & NR & NR & - & NR & NR & - \\
\hline
\end{tabular}

Bold values are statistically significant $(p<0.05)$

$Y o P$ year of publication, Min minutes, $N$ number, $N R$ not reported

${ }^{\mathrm{a}}$ Mean (SD), ${ }^{\mathrm{b}}$ median (range) 
Table 8 Incision length and tolerance to solid diet

\begin{tabular}{|c|c|c|c|c|c|c|}
\hline \multirow[t]{2}{*}{$\overline{\text { Study (author, YoP) }}$} & \multicolumn{3}{|l|}{ Incision length } & \multicolumn{3}{|c|}{ Tolerance to solid diet (days) } \\
\hline & IA & EA & $p$ & IA & EA & $p$ \\
\hline Anania, 2012 & NR & NR & - & $4.6(2.1)^{\mathrm{a}}$ & $5.7(1.7)^{\mathrm{a}}$ & $<0.0001$ \\
\hline Chaves, 2011 & NR & NR & - & $1(1-9)^{\mathrm{b}}$ & $2(1-10)^{\mathrm{b}}$ & 0.002 \\
\hline Fabozzi, 2010 & $6.0(1)^{\mathrm{a}}$ & $12.0(2)^{\mathrm{a}}$ & $<0.05$ & NR & NR & - \\
\hline Lee, 2013 & NR & NR & - & NR & NR & - \\
\hline Magistro, 2013 & $5.5(1.1)^{\mathrm{a}}$ & $7.2(1.3)^{\mathrm{a}}$ & 0.01 & NR & NR & - \\
\hline Marchesi, 2013 & $4.8(0.9)^{\mathrm{a}}$ & $7.2(1.1)^{\mathrm{a}}$ & 0.02 & NR & NR & - \\
\hline Milone, 2015 & NR & NR & - & NR & NR & - \\
\hline Roscio, 2012 & NR & NR & - & NR & NR & - \\
\hline Scatizzi, 2010 & $4.0(3.0-7.0)^{\mathrm{b}}$ & $5.0(3.0-7.0)^{\mathrm{b}}$ & 0.019 & $1(1-8)^{b}$ & $2(1-12)^{b}$ & 0.025 \\
\hline Shapiro, 2015 & NR & NR & - & NR & NR & - \\
\hline Trastulli, 2015 & NR & NR & - & NR & NR & - \\
\hline Vergis, 2015 & NR & NR & - & $2.34^{\mathrm{a}}$ & $3.21^{\mathrm{a}}$ & 0.023 \\
\hline
\end{tabular}

Bold values are statistically significant $(p<0.05)$

$Y o P$ year of publication, Min minutes, $N$ number, $N R$ not reported

${ }^{\mathrm{a}}$ Mean (SD), ${ }^{\mathrm{b}}$ median (range)

\section{References}

1. Ferlay J, Steliarova-Foucher E, Lortet-Tieulent J, Rosso S, Coebergh JW, Comber H, Forman D, Bray F (2013) Cancer incidence and mortality patterns in Europe: estimates for 40 countries in 2012. EurJCancer 49:1374-1403

2. Ferlay J, Soerjomataram I, Dikshit R, Eser S, Mathers C, Rebelo M, Parkin DM, Forman D, Bray F (2015) Cancer incidence and mortality worldwide: sources, methods and major patterns in GLOBOCAN 2012. Int J Cancer 136:E359-E386

3. Van Leersum NJ, Snijders HS, Henneman D, Kolfschoten NE, Gooiker GA, ten Berge MG, Eddes EH, Wouters MW, Tollenaar RA, Bemelman WA, Van Dam RM, Elferink MA, Karsten TM, Van Krieken JH, Lemmens VE, Rutten HJ, Manusama ER, van de Velde CJ, Meijerink WJ, Wiggers T, Van Der Harst E, Dekker JW, Boerma D (2013) The Dutch surgical colorectal audit. Eur J Surg Oncol 39:1063-1070

4. Schwenk W, Haase O, Neudecker J, Muller JM (2005) Short term benefits for laparoscopic colorectal resection. Cochrane Database Syst Rev (3):CD003145. doi:10.1002/14651858.CD003145.pub2

5. Vlug MS, Wind J, Hollmann MW, Ubbink DT, Cense HA, Engel $\mathrm{AF}$, Gerhards MF, van Wagensveld BA, van der Zaag ES, van Geloven AAW, Sprangers MAG, Cuesta MA, Bemelman WA (2011) Laparoscopy in combination with fast track multimodal management is the best perioperative strategy in patients undergoing colonic surgery: a randomized clinical trial (LAFA-study). Ann Surg 254:868-875

6. Kennedy RH, Francis EA, Wharton R, Blazeby JM, Quirke P, West NP, Dutton SJ (2014) Multicenter randomized controlled trial of conventional versus laparoscopic surgery for colorectal cancer within an enhanced recovery programme: EnROL. J Clin Oncol 32:1804-1811

7. Bergamaschi R, Schochet E, Haughn C, Burke M, Reed JF, Arnaud JP (2008) Standardized laparoscopic intracorporeal right colectomy for cancer: short-term outcome in 111 unselected patients. Dis Colon Rectum 51:1350-1355

8. Barnett RB, Clement GS, Drizin GS, Josselson AS, Prince DS (1992) Pulmonary changes after laparoscopic cholecystectomy. Surg Laparosc Endosc 2:125-127
9. Hellan M, Anderson C, Pigazzi A (2009) Extracorporeal versus intracorporeal anastomosis for laparoscopic right hemicolectomy. JSLS 13:312-317

10. Jamali FR, Soweid AM, Dimassi H, Bailey C, Leroy J, Marescaux J (2008) Evaluating the degree of difficulty of laparoscopic colorectal surgery. Arch Surg 143:762-767

11. Cirocchi R, Trastulli S, Farinella E, Guarino S, Desiderio J, Boselli C, Parisi A, Noya G, Slim K (2013) Intracorporeal versus extracorporeal anastomosis during laparoscopic right hemicolectomy-systematic review and meta-analysis. Surg Oncol 22:1-13

12. Carnuccio P, Jimeno J, Pares D (2014) Laparoscopic right colectomy: a systematic review and meta-analysis of observational studies comparing two types of anastomosis. Tech Coloproctol 18:5-12

13. Lee KH, Ho J, Akmal Y, Nelson R, Pigazzi A (2013) Short- and long-term outcomes of intracorporeal versus extracorporeal ileocolic anastomosis in laparoscopic right hemicolectomy for colon cancer. Surg Endosc 27:1986-1990

14. Magistro C, Lernia SD, Ferrari G, Zullino A, Mazzola M, De Martini P, De Carli S, Forgione A, Bertoglio CL, Pugliese R (2013) Totally laparoscopic versus laparoscopic-assisted right colectomy for colon cancer: is there any advantage in short-term outcomes? A prospective comparative assessment in our center. Surg Endosc 27:2613-2618

15. Marchesi F, Pinna F, Percalli L, Cecchini S, Ricco M, Costi R, Pattonieri V, Roncoroni L (2013) Totally laparoscopic right colectomy: theoretical and practical advantages over the laparoassisted approach. J Laparoendosc Adv Surg Tech A 23:418-424

16. Milone M, Elmore U, Di Salvo E, Delrio P, Bucci L, Ferulano GP, Napolitano C, Angiolini MR, Bracale U, Clemente M, D’Ambra M, Luglio G, Musella M, Pace U, Rosati R, Milone F (2015) Intracorporeal versus extracorporeal anastomosis. Results from a multicentre comparative study on 512 right-sided colorectal cancers. Surg Endosc 29:2314-2320

17. Shapiro R, Keler U, Segev L, Sarna S, Hatib K, Hazzan D (2015) Laparoscopic right hemicolectomy with intracorporeal anastomosis: short- and long-term benefits in comparison with extracorporeal anastomosis. Surg Endosc. doi:10.1007/s00464-0154684-x 
18. Trastulli S, Coratti A, Guarino S, Piagnerelli R, Annecchiarico M, Coratti F, Di Marino M, Ricci F, Desiderio J, Cirocchi R, Parisi A (2015) Robotic right colectomy with intracorporeal anastomosis compared with laparoscopic right colectomy with extracorporeal and intracorporeal anastomosis: a retrospective multicentre study. Surg Endosc 29:1512-1521

19. Vergis AS, Steigerwald SN, Bhojani FD, Sullivan PA, Hardy KM (2015) Laparoscopic right hemicolectomy with intracorporeal versus extracorporeal anastamosis: a comparison of short-term outcomes. Can J Surg 58:63-68

20. Moher D, Liberati A, Tetzlaff J, Altman DG (2009) Preferred reporting items for systematic reviews and meta-analyses: the PRISMA statement. J Clin Epidemiol 62:1006-1012

21. Slim K, Nini E, Forestier D, Kwiatkowski F, Panis Y, Chipponi J (2003) Methodological index for non-randomized studies (minors): development and validation of a new instrument. ANZJSurg 73:712-716

22. Mantel N, Haenszel W (1959) Statistical aspects of the analysis of data from retrospective studies of disease. J Natl Cancer Inst 22:719-748

23. Feroci F, Lenzi E, Garzi A, Vannucchi A, Cantafio S, Scatizzi M (2013) Intracorporeal versus extracorporeal anastomosis after laparoscopic right hemicolectomy for cancer: a systematic review and meta-analysis. Int J Colorectal Dis 28:1177-1186

24. Tarta C, Bishawi M, Bergamaschi R (2013) Intracorporeal ileocolic anastomosis: a review. Tech Coloproctol 17:479-485

25. Stein SA, Bergamaschi R (2013) Extracorporeal versus intracorporeal ileocolic anastomosis. Tech Coloproctol 17(Suppl 1):S35-S39

26. Grams J, Tong W, Greenstein AJ, Salky B (2010) Comparison of intracorporeal versus extracorporeal anastomosis in laparoscopicassisted hemicolectomy. Surg Endosc 24:1886-1891

27. Abrisqueta J, Ibanez N, Lujan J, Hernandez Q, Parrilla P (2016) Intracorporeal ileocolic anastomosis in patients with laparoscopic right hemicolectomy. Surg Endosc 30(1):65-72

28. Iorio T, Blumberg D (2014) A case-control study examining the benefits of laparoscopic colectomy using a totally intracorporeal technique for left-sided colon tumors. Surg Laparosc Endosc Percutan Tech 24:381-384

29. Franklin ME Jr, Gonzalez JJJ, Miter DB, Mansur JH, Trevino JM, Glass JL, Mancilla G, Abrego-Medina D (2004) Laparoscopic right hemicolectomy for cancer: 11-year experience. Rev Gastroenterol Mex 69(Suppl 1):65-72

30. Feroci F, Lenzi E, Kroning KC, Moraldi L, Cantafio S, Borrelli A, Giaconi G, Scatizzi M (2011) Feasibility and effectiveness of laparoscopic right colectomy with extracorporeal anastomosis. Minerva Chir 66:41-48

31. Moghadamyeghaneh Z, Carmichael JC, Mills S, Pigazzi A, Nguyen NT, Stamos MJ (2015) Hand-assisted laparoscopic approach in colon surgery. J Gastrointest Surg 19:2045-2053

32. Anania G, Santini M, Scagliarini L, Marzetti A, Vedana L, Marino S, Gregorio C, Resta G, Cavallesco G (2012) A totally mini-invasive approach for colorectal laparoscopic surgery. World J Gastroenterol 18:3869-3874

33. Chaves JA, Idoate CP, Fons JB, Oliver MB, Rodriguez NP, Delgado AB, Lizoain JLH (2011) A case-control study of extracorporeal versus intracorporeal anastomosis in patients subjected to right laparoscopic hemicolectomy. Cir Esp 89:24-30

34. Fabozzi M, Allieta R, Brachet Contul R, Grivon M, Millo P, Lale-Murix E, Nardi M Jr (2010) Comparison of short- and medium-term results between laparoscopically assisted and totally laparoscopic right hemicolectomy: a case-control study. Surg Endosc 24:2085-2091

35. Roscio F, Bertoglio C, De Luca A, Frattini P, Scandroglio I (2012) Totally laparoscopic versus laparoscopic assisted right colectomy for cancer. Int J Surg 10:290-295

36. Scatizzi M, Kroning KC, Borrelli A, Andan G, Lenzi E, Feroci F (2010) Extracorporeal versus intracorporeal anastomosis after laparoscopic right colectomy for cancer: a case-control study. World J Surg 34:2902-2908

37. Singh R, Omiccioli A, Hegge S, McKinley C (2008) Does the extraction-site location in laparoscopic colorectal surgery have an impact on incisional hernia rates? Surg Endosc 22:2596-2600

38. Winslow ER, Fleshman JW, Birnbaum EH, Brunt LM (2002) Wound complications of laparoscopic vs open colectomy. Surg Endosc 16:1420-1425

39. Kisielinski K, Conze J, Murken AH, Lenzen NN, Klinge U, Schumpelick V (2004) The Pfannenstiel or so called "bikini cut": still effective more than 100 years after first description. Hernia 8:177-181

40. Leung AL, Cheung HY, Fok BK, Chung CC, Li MK, Tang CN (2013) Prospective randomized trial of hybrid NOTES colectomy versus conventional laparoscopic colectomy for left-sided colonic tumors. World J Surg 37:2678-2682

41. Jenks PJ, Laurent M, McQuarry S, Watkins R (2014) Clinical and economic burden of surgical site infection (SSI) and predicted financial consequences of elimination of SSI from an English hospital. J Hosp Infect 86:24-33

42. Blumberg D (2009) Laparoscopic colectomy performed using a completely intracorporeal technique is associated with similar outcome in obese and thin patients. Surg Laparosc Endosc Percutan Tech 19:57-61

43. Lechaux D (2005) Intra-corporeal anastomosis in laparoscopic right hemicolectomy. J Chir (Paris) 142:102-104

44. Chang K, Fakhoury M, Barnajian M, Tarta C, Bergamaschi R (2013) Laparoscopic right colon resection with intracorporeal anastomosis. Surg Endosc 27:1730-1736

45. Kayaalp C, Yagci MA (2015) Laparoscopic right colon resection with transvaginal extraction: a systematic review of 90 cases. Surg Laparosc Endosc Percutan Tech 25:384-391

46. Wolthuis AM, de Buck van Overstraeten A, D'Hoore A (2014) Laparoscopic natural orifice specimen extraction-colectomy: a systematic review. World J Gastroenterol 20:12981-12992 